\title{
Comparative Study of Colorectal Cancer Based on Tumor Location in Adolescent and Young Adult Population in Nepal
}

\author{
Rajeeb K Deo ${ }^{1}$, Prakash G Chitalkar², Srijan Malla ${ }^{3}$, Bikash Shrestha ${ }^{4}$, Kunda B \\ $\mathrm{Shah}^{3}$, Binod Karki ${ }^{1}$
}

${ }^{1}$ Department of Medicine, Shree Birendra Hospital, Chhauni, Kathmandu, Nepal

${ }^{2}$ Sri Aurobindo Institute of Medical Sciences, Indore

${ }^{3}$ Department of Surgery, Shree Birendra Hospital, Chhauni, Kathmandu, Nepal

${ }^{4}$ Department of Pediatrics, Shree Birendra Hospital, Chhauni, Kathmandu, Nepal

\section{ABSTRACT}

Introduction: Colorectal cancer in the Adolescent and Young Adult population are increasing and are characterized by a more advanced stage at diagnosis, poorer cell differentiation, higher signet ring histology, and left-sided colon location of the primary tumor. This study aims to compare colorectal cancer data in the Adolescent and Young Adult population-based on tumor location.

Materials and Methods: This is a retrospective cross-sectional study of colorectal cancer in the Adolescent and Young Adult population from April 2017 to September 2020 in Shree Birendra Hospital. Data were collected for age, sex, clinical features, histology, TNM stage, colonoscopy finding, radiologic features, treatment, and follow-up status based on tumor location. Data were analyzed using Excel 2010 and SPSS v 17.

Results: The total number of patients was 61 with the mean age of $32.36 \pm 6.24$ years. There was a male preponderance of $63.93 \%$. Right-sided colorectal cancer was $24.59 \%$ while left-sided colorectal cancer was $75.41 \%$. For right-sided colorectal cancers, the most common symptoms were pain abdomen $(73.3 \%)$ and diarrhea $(53.3 \%)$ while for left-sided colorectal cancers, it was pain abdomen $(80.4 \%)$ and bleeding per rectum $(45.7 \%)$. The most common histology was adenocarcinoma (95.08\%) with moderately differentiated being most common in both locations. Surgery, radiation and chemotherapy for right-sided and left-sided colorectal cancer were $86.66 \%$, $0.0 \%, 86.66 \%$ and $58.67 \%, 28.26 \%, 89.13 \%$ respectively.

Conclusions: Left-sided colorectal cancer was more common in the Adolescent and Young Adult population in our study. There were significant differences in the clinical presentation of colorectal cancer as per the tumor location.

Keywords: Adolescent; Colorectal cancer; Tumor location; Young adult
Correspondence:

Dr. Rajeeb Kumar Deo

Medical Oncologist, Department of Internal Medicine Shree Birendra Hospital, Chhauni, Kathmandu, Nepal ORCID ID: 0000-0002-7808-9717

Email: rajeebdeo@yahoo.com

Submitted: $10^{\text {th }}$ November 2020 Accepted: $18^{\text {th }}$ December 2020

Source of Support: None Conflict of Interest: None

Citation: Deo RK, Chitalkar PG, Malla S, Shrestha B, Shah KB, Karki B. Comparative study of colorectal cancer based on tumor location in adolescent and young adult population in Nepal. NMJ 2020;3(2):3704. DOI $10.3126 / \mathrm{nmj} . \mathrm{v} 3 \mathrm{i} 2.33087$ 


\section{INTRODUCTION}

Adolescent and Young Adult (AYA) with cancer are distinguished by physiological, developmental, and societal characteristics that set them apart from younger and older age groups. ${ }^{1}$ Adolescent and Young Adult Oncology Progress Review Group, with consensus from National Cancer Institute (NCI) and the European Network for Cancer Research in Children and Adolescents (ENCCA), agree in defining the AYA population as comprising individuals aged 15 through 39 years at cancer diagnosis, with 15 to 19 years being Adolescents. ${ }^{1}$ The global cancer burden among 20-39 yearolds differs from that in younger or older ages but also varies substantially by age, sex, development level, and geographical region. ${ }^{2}$ Over the last 30 years, AYA oncology patients have not shared the improvement of cure rate obtained for the children with cancer. ${ }^{3}$ Cancer occurring between the ages of 15 and 39 years is 4 times less rare than cancer occurring during the first 15 years of life. ${ }^{4}$

Colorectal cancer (CRC) incidence in the AYA population has been increasing by $2 \%$ per year. The surge in CRC incidence in young adults is particularly alarming as the overall CRC frequency has been decreasing. ${ }^{5} \mathrm{CRC}$ in the AYA population are characterized by a more advanced stage at diagnosis, poorer cell differentiation, higher prevalence of signet ring cell histology, and left-sided colon location of the primary tumor. ${ }^{5}$ Young patients with colorectal cancer have several distinct clinic-pathological and molecular biological features. ${ }^{6}$ Though initial signs and symptoms of CRC are similar in pediatric and adult patients, the strikingly higher frequency of mucinous histology suggests that the biology of CRC differs in pediatric and adult patients and may contribute to poor outcomes. ${ }^{7} \mathrm{CRC}$ in young adults presents more frequently with stage 3 or 4 diseases, underscoring its relevance in this population. The prognosis of the CRC is similar when matched for the stage of disease at presentation however the survival is lower for the youngest subgroups. ${ }^{8}$

This study aims to compare colorectal cancer in the AYA population-based on tumor location and describe age \& sex distribution, clinical features, histology, TNM stage, radiologic features, treatment, and follow-up status based on tumor location. Cancers proximal or distal of the splenic flexure were classified as right-sided or left-sided, respectively. ${ }^{9}$

\section{MATERIALS AND METHODS}

This is a retrospective cross-sectional study of patients diagnosed with Colorectal Cancer (CRC) in the Adolescent and Young Adult (AYA) population (defined as patients in the age group 15 to 39 years) attending Shree Birendra Hospital. The study was approved by Institutional Review Committee.

The data were collected from the Oncology Unit registry. Data of patients diagnosed with CRC were collected from April 2017 to September 2020. All AYA patients diagnosed with CRC during this period were included in the study. Those patients whose diagnoses were uncertain or have inadequate records were excluded. Diagnosis of CRC was based on colonoscopy findings, CT scan imaging, and tissue biopsy. Tumors located in the caecum, ascending colon, hepatic flexure, and transverse colon was considered right-sided CRC while tumors located in splenic flexure, descending colon, sigmoid, recto-sigmoid, and rectum are considered left-sided CRC. The staging was done using TNM classification. Data were collected for age, sex, clinical features, histology, TNM stage, colonoscopy finding, radiologic features, treatment, and follow-up status based on tumor location. Continuous variables were expressed as mean \pm standard deviation (SD) and categorical variables as numbers and frequencies. Categorical variables were compared using the $\chi 2$ test and continuous variables with the independent t-test. Data were analyzed using Excel 2010 and SPSS v 17.

\section{RESULTS}

The total number of patients included in this study was 61 . The mean age of the study population was $32.36 \pm 6.24$. There was a male preponderance of $63.93 \%(\mathrm{M}: \mathrm{F}=1.7: 1)$. The most common presenting symptoms were pain abdomen $(78.69 \%)$ followed by bleeding Per Rectum (PR) (34.43\%), mass PR (16.39\%), constipation $(18.03 \%)$, and diarrhea (22.95\%). Right-sided CRC was $24.59 \%$ while left-sided CRC was $75.41 \%$. The most common site of the tumor was the rectum $(49.18 \%)$.

Table 1: Baseline characteristic of the study population

\begin{tabular}{|c|c|c|}
\hline Parameters & & Values \\
\hline & Age in years $($ Mean \pm SD) & $32.36 \pm 6.24$ \\
\hline \multicolumn{2}{|c|}{ Male } & $39(63.93 \%)$ \\
\hline \multirow[t]{5}{*}{ Age group (years) } & 15 to 19 & $4(6.56 \%)$ \\
\hline & 20 to 24 & $4(6.56 \%)$ \\
\hline & 25 to 29 & $6(9.84 \%)$ \\
\hline & 30 to 34 & $23(37.7 \%)$ \\
\hline & 25 to 39 & $24(39.34 \%)$ \\
\hline \multirow[t]{5}{*}{ Clinical features } & Pain abdomen & $48(78.69 \%)$ \\
\hline & Bleeding per rectum & $21(34.43)$ \\
\hline & Mass per rectum & $10(16.39)$ \\
\hline & Constipation & $11(18.03 \%)$ \\
\hline & Diarrhea & $14(22.95 \%)$ \\
\hline
\end{tabular}




\begin{tabular}{|c|c|c|}
\hline Parameters & & Values \\
\hline \multirow[t]{4}{*}{ Right-sided CRC } & Caecum & $3(4.92 \%)$ \\
\hline & Ascending Colon & $5(8.2 \%)$ \\
\hline & Hepatic flexure & $3(4.92 \%)$ \\
\hline & Transverse colon & $4(6.56 \%)$ \\
\hline Total & $15(24.59 \%)$ & \\
\hline \multirow[t]{5}{*}{ Left-sided CRC } & Splenic flexure & $1(1.64 \%)$ \\
\hline & Descending colon & $6(9.84 \%)$ \\
\hline & Sigmoid & $2(3.28 \%)$ \\
\hline & Rectosigmoid & $7(11.48 \%)$ \\
\hline & Rectum & $30(49.18 \%)$ \\
\hline Total & $46(75.41 \%)$ & \\
\hline \multirow[t]{3}{*}{ Histology } & Adeno Carcinoma & $58(95.08 \%)$ \\
\hline & GIST & $1(1.64 \%)$ \\
\hline & NHL & $2(3.28 \%)$ \\
\hline
\end{tabular}

The most common histology was adenocarcinoma (95.08\%). The most common histologic subtypes in right-sided CRC were moderately differentiated (33.30\%) followed by mucinous (26.70\%), poorly differentiated $(20.06 \%)$, and well-differentiated (13.3\%). For left-sided CRC, common histologic subtypes were moderately-differentiated (28.3\%), mucinous (28.3\%), and well-differentiated (19.6\%). (Table 2)

Table 2: Histology Subtypes of Adenocarcinoma as per the tumor location of CRC in the study population

\begin{tabular}{lllll}
\hline Histology Subtypes & Rt sided CRC $(\mathbf{n = 1 5})$ & $\begin{array}{c}\text { Site of tumor } \\
\text { Lt side CRC }(\mathbf{n = 4 6})\end{array}$ & Total (n=61) & P-value \\
\hline Well differentiated & $2(13.33 \%)$ & $9(19.56 \%)$ & 11 \\
\hline Moderately differentiated & $5(33.33 \%)$ & $13(28.26 \%)$ & 18 & $0.68^{*}$ \\
\hline Poorly differentiated & $3(20.0 \%)$ & $3(6.52 \%)$ & 4 & 17 \\
\hline Signet ring & $0(0.0 \%)$ & $4(8.69 \%)$ & 2 & \\
\hline Mucinous & $4(26.66 \%)$ & $13(28.26 \%)$ & $2(4.34 \%)$ & \\
\hline Neuroendocrine & $0(0.0 \%)$ & &
\end{tabular}

*Fisher's Exact Test

For right-sided CRC, the most common symptoms were pain abdomen (73.3\%) and diarrhea (53.3\%) while for left-sided CRC; the most common symptoms were pain abdomen $(80.4 \%)$ and bleeding per rectum $(45.7 \%)$. (Table 3 )

Table 3: Clinical features as per the tumor location in CRC in the study population

\begin{tabular}{llll}
\hline \multicolumn{3}{c}{ Site of tumor } \\
Symptoms & $\begin{array}{l}\text { Rt sided CRC } \\
(\mathbf{n}=15)\end{array}$ & $\begin{array}{l}\text { Lt sided CRC } \\
\mathbf{( n = 4 6 )}\end{array}$ & P-value \\
\hline $\begin{array}{l}\text { Bleeding per } \\
\text { rectum }\end{array}$ & $0(0.0 \%)$ & $21(45.65 \%)$ & $0.001^{*}$ \\
\hline $\begin{array}{l}\text { Pain } \\
\text { abdomen }\end{array}$ & $11(73.33 \%)$ & $37(80.43 \%)$ & $0.718^{*}$ \\
\hline $\begin{array}{l}\text { Mass per } \\
\text { rectum }\end{array}$ & $0(0.0 \%)$ & $10(21.74 \%)$ & $0.055^{*}$ \\
\hline Constipation & $6(40.0 \%)$ & $5(10.87 \%)$ & $0.019^{*}$ \\
\hline Diarrhea & $8(53.33 \%)$ & $6(13.04 \%)$ & $0.003^{*}$ \\
\hline
\end{tabular}

*Fisher's Exact Test

Both right and left-sided CRC presented late with the stage of presentation as depicted in table 4. Stage III was the most common for both (Right-sided vs. Left sided $=46.7 \%$ vs. $5.7 \%$ ).
Table 4: Tumor stages as per tumor location in CRC in the study population

\begin{tabular}{|c|c|c|c|}
\hline \multirow{2}{*}{ Symptoms } & \multicolumn{2}{|c|}{ Site of tumor } & \multirow{2}{*}{ P-value } \\
\hline & Rt sided CRC $(n=15)$ & Lt sided CRC $(n=46)$ & \\
\hline Stage I & $2(13.33)$ & $12(26.01 \%)$ & \multirow{4}{*}{$0.70^{*}$} \\
\hline Stage II & $5(33.33 \%)$ & $11(23.91 \%)$ & \\
\hline Stage III & $7(46.67 \%)$ & $21(45.65 \%)$ & \\
\hline Stage IV & $1(6.67 \%)$ & $2(4.35 \%)$ & \\
\hline
\end{tabular}

*Fisher's Exact Test

Right hemicolectomy was performed in $86.66 \%(n=13)$ in rightsided CRC while $13.33 \%$ did not undergo surgery. None of the patients received radiation. The most common chemotherapy regimen used for right-sided CRC was FOLFOX-4 (14.75\%), followed by FOLFIRI (3.27\%) and CAPEOX (1.64\%). One patient $(1.64 \%)$ received $\mathrm{R}-\mathrm{CHOP}$ while two $(3.27 \%)$ did not receive chemotherapy (Table 5).

For left-sided CRC $(\mathrm{n}=46)$, surgeries performed were abdominoperineal resection (APR) 26.08\%, low anterior resection (LAR) $15.21 \%$, left hemicolectomy $15.21 \%$ and sigmoidectomy $2.17 \%$ while 19 patients $(41.30 \%)$ did not undergo any surgery. Radiation was given in $28.26 \%$ of left side CRC. The most common chemotherapy regimen used for left-sided CRC was 
FOLFOX-4 (31.14\%), followed by LV+5FU (16.4\%), CAPEOX (11.47\%), FOLFIRI (4.91\%). One patient (1.64\%) received R-CHOP, one patient (1.64\%) received Imatinib while five patients $(8.19 \%)$ did not receive chemotherapy (Table 5$)$.

Table 5: Treatment of CRC in AYA among the study population

\begin{tabular}{|c|c|c|c|c|c|}
\hline Treatment Modality & Procedure & Rt sided CRC $(n=15)$ & Lt sided CRC (n=46) & Total & P-value \\
\hline \multirow{7}{*}{ Surgery } & Rt Hemicolectomy & $13(86.66 \%)$ & $0(0 \%)$ & $13(21.31 \%)$ & \multirow{7}{*}{$<0.001^{*}$} \\
\hline & $\mathbf{A P R}$ & $0(0 \%)$ & $12(26.08 \%)$ & $12(19.67 \%)$ & \\
\hline & LAR & $0(0 \%)$ & $7(15.21 \%)$ & $7(11.47 \%)$ & \\
\hline & Lt Hemicolectomy & $0(0 \%)$ & $7(15.21 \%)$ & $7(11.47 \%)$ & \\
\hline & Sigmoidectomy & $0(0 \%)$ & $1(2.17 \%)$ & $1(1.63 \%)$ & \\
\hline & None & $2(13.33 \%)$ & $19(41.30 \%)$ & $21(34.42 \%)$ & \\
\hline & Total & $15(100 \%)$ & $46(100 \%)$ & $61(100 \%)$ & \\
\hline \multirow{3}{*}{ Radiation } & CCRT & $0(0 \%)$ & $13(28.26 \%)$ & $13(21.31 \%)$ & \multirow{3}{*}{$0.026^{*}$} \\
\hline & None & $15(100.0 \%)$ & $33(71.74 \%)$ & $48(78.68 \%)$ & \\
\hline & Total within location of tumor & $15(100.0 \%)$ & $46(100.0 \%)$ & $61(100 \%)$ & \\
\hline \multirow{8}{*}{ Chemotherapy } & FOLFOX & $9(14.75 \%)$ & $19(31.14 \%)$ & $28(45.90 \%)$ & \multirow{8}{*}{$0.252 *$} \\
\hline & FOLFIRI & $2(3.27 \%)$ & $3(4.91 \%)$ & $5(8.19 \%)$ & \\
\hline & CAPEOX & $1(1.64 \%)$ & $7(11.47 \%)$ & $8(13.11 \%)$ & \\
\hline & $\mathbf{L V}+\mathbf{5 F U}$ & $0(0 \%)$ & $10(16.4 \%)$ & $10(16.4 \%)$ & \\
\hline & R-CHOP & $1(1.64 \%)$ & $1(1.64 \%)$ & $2(3.27 \%)$ & \\
\hline & Imatinib & $0(0 \%)$ & $1(1.64 \%)$ & $1(1.64 \%)$ & \\
\hline & None & $2(3.27 \%)$ & $5(8.19 \%)$ & $7(11.47 \%)$ & \\
\hline & Total & $15(24.59 \%)$ & $46(75.41 \%)$ & $61(100 \%)$ & \\
\hline
\end{tabular}

*Fisher's Exact Test

$\mathrm{LV}=$ Leucovorin, 5FU $=5$ Fluorouracil, CAPEOX $=$ Capecitabine and Oxaliplatin, R-CHOP $=$ (Rituximab, Cyclophosphamide, Doxorubicin, Vincristine, and Prednisolone)

Among patients receiving radiation $(\mathrm{n}=13 ; 21.32 \%$ of total), $69.23 \%$ received $\mathrm{LV}+5 \mathrm{FU}$ infusion while $30.77 \%$ received CAPEOX. (Table 6)

Table 6: Chemotherapy for patients receiving radiation in CRC in AYA

\begin{tabular}{lllll}
\hline Chemotherapy & CCRT & No CCRT & Total & P-value \\
\hline CAPEOX & $4(30.77 \%)$ & $4(8.33 \%)$ & $8(13.11 \%)$ & \\
\cline { 1 - 4 } LV+5FU & $9(69.23 \%)$ & $1(2.08 \%)$ & $10(16.4 \%)$ & $<0.001$ \\
\cline { 1 - 3 } Total & $13(21.32 \%)$ & $48(78.68 \%)$ & $61(100 \%)$ & \\
\cline { 1 - 3 } & & &
\end{tabular}

$\mathrm{LV}=$ Leucovorin, $5 \mathrm{FU}=5$ Fluorouracil, $\mathrm{CAPEOX}=$ Capecitabine and Oxaliplatin

\section{DISCUSSION}

The mean age of the CRC amongst young was similar to the published data from Nepal where the mean age was $34.1 \pm 4.7$ for patients diagnosed during 1999 to 2003 while the mean age was $31.8 \pm 5.1$ in patients diagnosed during 2004 to 2008.10 In a Netherland data of AYA CRC patients aged less than 25 years, there was $58 \%$ male preponderance whereas our data had $63.93 \%$ male preponderance. ${ }^{11}$ Age and gender distribution in our study are similar to other studies.

The most common clinical presentation in our study was the pain abdomen followed by bleeding per rectum. This was in contrast with the study from Nepal where bleeding per rectum $(70.6 \%)$ was more common than abdominal pain (57.1\%). ${ }^{10}$ In a study done across all ages in one of the teaching hospitals of Nepal, pain abdomen (86\%) and bleeding per rectum $(55 \%)$ were common symptoms at presentation. ${ }^{12}$
Our study showed more left-sided tumors compared to right-sided. The left-sided tumor was more common in metastatic CRC in a study with a large sample size ${ }^{9}$ while in a large data of patients across all ages, $67.03 \%$ of patients had right-sided CRC while $32.96 \%$ patients had left-sided CRC. ${ }^{13}$ In another study, there were $47.9 \%$ patients with right-sided CRC and $52.1 \%$ patients with left-sided CRC. ${ }^{14}$ Thus the site of the tumor is not consistent in various studies. The most common site of the tumor was the rectum $(49.18 \%)$ in our study and other studies also showed a similar distribution of tumor site. ${ }^{10,12,15}$

The most common histology was adenocarcinoma (95.08\%). The most common histologic subtypes in right-sided CRC were moderately differentiated followed by mucinous, poorly differentiated, and welldifferentiated. For left-sided CRC, common histologic subtypes were moderately differentiated, mucinous, and well-differentiated. This finding was similar to another Nepalese data of patients across all ages, where moderately differentiated $(70 \%)$ was the most common histology, followed by mucinous $(20 \%)^{12}$ whereas, in another study of childhood and adolescence patients, mucinous (62\%) was most common histology. ${ }^{7,16}$ The various subtypes within the histology group were compared as per the tumor location however the difference was not significant.

For right-sided $\mathrm{CRC}$, the most common symptoms were pain abdomen and diarrhea while for left-sided CRC; the most common symptoms were pain abdomen and bleeding per rectum. When the clinical features were compared in right vs. left-sided CRC, the left-sided tumor was more likely to present with bleeding per rectum $(\mathrm{p}=0.001)$ and constipation $(\mathrm{p}=0.019)$ whereas diarrhea $(\mathrm{p}=0.003)$ was more common in right-sided tumor and the differences observed were statistically significant. Pain abdomen was a predominant feature in all CRC and was not different within the tumor location $(p=0.68)$. The relatively narrow anatomical space explains more symptoms in the left-sided tumor which can lead to early presentation and tumor diagnosis. Studies have shown that the overall survival is better in left-sided cancer ${ }^{14}$ however survival data were not available for our study. 
Both right and left-sided CRC presented late with a stage of presentation. Stage III was most common for both. There was no significant difference in the stages as per tumor location $(\mathrm{p}=0.70)$. In another study, stage III $(40.3 \%)$ was the most common stage of presentation in CRC in AYA less than 25 years. ${ }^{11}$ In a study by Weiss JM et al, at presentation stage I, II, and III in right-sided CRC was $23.3 \%, 44.3 \%$, and 32.35 while left-sided CRC was $26.3 \%, 42.8 \%$, and $31 \%$ in mortality by stage as per tumor location in a large sample size. ${ }^{13}$

In right-sided CRC, surgery was the most common modality of treatment with the majority undergoing right hemicolectomy. The rate of surgery done for right-sided CRC was comparable with another study (86.66 vs. $96 \%$ ) while for left-sided CRC rate of surgery was lower in our study (58.7\% vs. $95.4 \%){ }^{14}$ In left-sided CRC, $28.26 \%$ of the patients received radiation and most of them received $\mathrm{LV}+5 \mathrm{FU}$ infusion as chemo-sensitizer.
The rate of radiation was comparable on both sides. ${ }^{14}$ Chemotherapy regimens used for both sides varied in different studies with FOLFOX, FOLFIRI, and CAPEOX being the most common regimens. ${ }^{7,9,14}$

This is one of the first studies of this kind in a Nepalese population. The limitation of the study is due to its retrospective nature. We could not evaluate the difference in survival as per the tumor location.

\section{CONCLUSIONS}

CRC is not uncommon in the Adolescent and Young Adult population in Nepal. The most common histopathology was adenocarcinoma and pain abdomen was the most common presenting symptom. There were significant differences in the clinical features as per the tumor location.

\section{REFERENCES}

1. Adolescent and Young Adult Oncology Progress Review Group: Closing the Gap: Research and Care Imperatives for Adolescents and Young Adults with Cancer. Bethesda, MD, Department of Health and Human Services, National Institutes of Health, National Cancer Institute, and the LiveStrong Young Adult Alliance, 2006. Available from: Website

2. Fidler M, Gupta S, Soerjomataram I, Ferlay J, Steliarova-Foucher E, Bray F. Cancer incidence and mortality among young adults aged 20 39 years worldwide in 2012: a population-based study, Lancet Oncol 2017; 18: 1579-89. $\underline{\text { Crossref }}$

3. Tai E, Buchanan N, Eliman D, Westervelt L, Beaupin L, Lawvere $\mathrm{S}$, et al. Understanding and addressing the lack of clinical trial enrollment among adolescents with cancer. Pediatrics. 2014 Jun;133 Suppl 3(Suppl 3):S98-103. Crossref

4. Desandes E, Stark DP. Epidemiology of Adolescents and Young Adults with Cancer in Europe. Prog Tumor Res. 2016;43:1-15. $\underline{\text { Crossref }}$

5. Mauri G, Sartore-Bianchi A, Russo AG, Marsoni S, Bardelli A, Siena S. Early-onset colorectal cancer in young individuals. Mol Oncol. 2019;13(2):109-31. Crossref

6. Liang JT, Huang KC, Cheng AL, Jeng YM, Wu MS, Wang SM. Clinicopathological and molecular biological features of colorectal cancer in patients less than 40 years of age. BJS 2003; 90: 205-14. Crossref

7. Hill DA, Furman WL, Billups CA, Riedley SE, Cain AM, Rao $\mathrm{BN}$, et al. Colorectal carcinoma in childhood and adolescence: a clinicopathologic review. J Clin Oncol. 2007;25(36):5808-14. Crossref

8. Zbuk K, Sidebotham EL, Bleyer A, La Quaglia MP. Colorectal cancer in young adults. Semin Oncol. 2009;36(5):439-50. Crossref
9. Loupakis F, Yang D, Yau L, Feng S, Cremolini C, Zhang W et al. Primary Tumor Location as a Prognostic Factor in Metastatic Colorectal Cancer, JNCI: Journal of the National Cancer Institute 2015;107:dju427. Crossref

10. Kansakar P, Singh Y. Changing Trends of Colorectal Carcinoma in Nepalese Young Adults. Asian Pacific Journal of Cancer Prevention. 2012;13(7):3209-12. $\underline{\text { Crossref }}$

11. De Voer RM, Diets IJ, van der Post RS, Weren RDA, Kamping EJ, de Bitter TJJ, et al. Clinical, Pathology, Genetic, and Molecular Features of Colorectal Tumors in Adolescents and Adults 25 Years or Younger. Clinical Gastroenterology and Hepatology [Internet]. Elsevier BV; 2020. Crossref

12. Paudyal S, KC SR, Maharjan S, Shah S, Giri N, KC S, et al. Clinicopathological profile of colorectal cancer managed at a university teaching hospital, Nepal. Journal of Patan Academy of Health Sciences. Nepal Journals Online (JOL);2019;6(2):31-8. $\underline{\text { Crossref }}$

13. Weiss JM, Pfau PR, O'Connor ES, King J, LoConte N, Kennedy G, et al. Mortality by stage for right- versus left-sided colon cancer: analysis of surveillance, epidemiology, and end results--Medicare data. J Clin Oncol. 2011;29(33):4401-9. $\underline{\text { Crossref }}$

14. He XK, Wu W, Ding YE, Li Y, Sun LM, Si J. Different Anatomical Subsites of Colon Cancer and Mortality: A Population-Based Study. Gastroenterol Res Pract. 2018;2018:7153685. Crossref

15. Rawal S, Laudari U, Thapa A, Jha M, Shrestha D, Maharjan M, et al Colorectal Cancer in Young Age Group: Where Do We Stand?. Nepal Medical College Journal. 2019;21(2), 104-9. Crossref

16. Tohmé C, Labaki M, Hajj G, Abboud B, Noun R, Sarkis R. Le cancer colorectal du sujet jeune: présentation, caractéristiques clinicopathologiques et pronostic [Colorectal cancer in young patients:presentation, clinicopathological characteristics and outcome]. J Med Liban. 2008;56(4):208-14. Website 